\title{
HARPACTEA KARASCHKHAN SP. N., A NEW CAVE-DWELLING BLIND SPIDER SPECIES FROM THE MEDITERRANEAN REGION OF TURKEY
}

\author{
Kadir BoĞaÇ Kunt', Recep Sulhi ÖzkütüK', Mert Elverici ${ }^{2,3}$, \\ Yuri M. MarusiK ${ }^{4,5}$, And Gizem KaraKaș ${ }^{1}$
}

\begin{abstract}
A new troglobitic species, Harpactea karaschkhan sp. n. (females only), inhabiting Yalandünya Mağarası of Gazipaşa (Antalya Province, Turkey) is described. Detailed morphological description and illustrations of the new species are provided. The relationships of the new species are discussed.
\end{abstract}

\section{INTRODUCTION}

Obligatory cave-dwelling organisms (troglobionts) have attracted attention of the scientific community for almost two centuries. Evolution of troglomorphic traits, such as loss of eyes and pigment, or gains, such as elongated appendages and increases in number or functionality of nonvisual sense organs, often obscures taxonomic relationships due to convergence. On the other hand, narrow distribution ranges and high endemism make troglobionts important subjects of biogeographic studies (Porter, 2007).

In spiders, troglomorphy usually results in loss of eyes and depigmentation. Such species are rather common, although their number varies within family or genus. One of the richest groups in troglobionts is the subfamily Harpacteinae in family Dysderidae.

Among Harpacteinae, reduction of eyes is common in the genera Folkia Kratochvíl, 1970 and Stalagtia Kratochvíl, 1970; eyes are absent in the monotypic genus Sardostalita Gasparo, 1999; and eyes are reduced in Minotauria attemsi Kulczyński, 1903 and completely absent in M. fagei (Kratochvíl, 1970). With only a few exceptions, species in the genus Harpactea Bristowe, 1939 possess fully developed eyes. Eyes are strongly reduced in $H$. persephone Gasparo, 2011 (Kournas Cave, Chania Prefecture, Crete, Greece), and posterior median eyes are absent in H. sanctidomini Gasparo, 1997 (Tremiti Islands, Italy). Eyes are completely lost in Harpactea only in two known cases, H. stalitoides Ribera, 1993 (Iberian Peninsula) and H. strinatii Brignoli, 1979 (Diros Caves, Peloponnese, Greece).

The third known case of a completely blind Harpactea is the new species Harpactea karaschkhan sp. n., described here from Turkey. Our description is based on females; the male is unknown. Illustrations of taxonomically important body parts and female reproductive organs are provided.

\section{Material And Methods}

Studied material was collected from the type locality, on the walls of the cave by using a hand aspirator. The specimens were preserved in 70\% ethanol and deposited in the Anadolu University Zoology Museum. Digital images of copulatory organs were taken with a Leica DFC295 digital camera attached to a Leica S8AP0 stereomicroscope; five to fifteen photographs were taken in different focal planes and combined using Automontage software. All measurements are in $\mathrm{mm}$, with methods following Chatzaki and Arnedo (2006). Terminology for the copulatory organs is adapted from Deeleman-Reinhold (1993).

The following abbreviations are used in the description: Dimensions of carapace and abdomen, AL, abdominal length; CL, carapace length, CWmax, maximum carapace width; CWmin, minimum carapace width. Chelicera: $\mathrm{ChF}$, length of cheliceral fang; $\mathrm{ChG}$, length of cheliceral groove; $\mathrm{ChL}$, total length of chelicera (lateral external view). Depository: AUZM, Anadolu University Zoology Museum, Eskişehir, Turkey.

\section{TAXONOMY}

HARPACTEA BRISTOWE, 1939

HARPACTEA KARASCHKHAN SP, N.

Material examined. Holotype $\subsetneq$ (AUZM), Turkey, Antalya Province, Gazipaşa District, Beyrebucak Village,

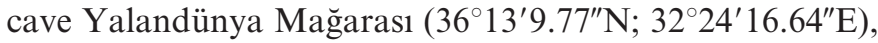
05 January 2013, K.B. Kunt leg. Paratypes 1 \&, 1 juvenile (AUZM), same locality and date as holotype, Y.M. Marusik leg.

Diagnosis: Harpactea karaschkhan sp. n. can be easily distinguished from other species of Harpactea found in Turkey and elsewhere by its troglomorphic characters and presence of retrolateral spines on anterior femora, normally absent in this genus. While the new species is similar to the Cretan endemic Harpactea persephone in the

\footnotetext{
${ }^{1}$ Department of Biology, Faculty of Science, Anadolu University, TR- 26470 Eskişehir, Turkey

${ }^{2}$ Department of Biological Sciences, Faculty of Arts and Sciences, Middle East Technical University, TR-06800 Ankara, Turkey

${ }^{3}$ Department of Biology, Faculty of Science and Arts, University of Erzincan, TR24100, Erzincan, Turkey

${ }^{4}$ Institute for Biological Problems of the North RAS, Portovaya Str. 18, Magadan, Russia

${ }^{5}$ Department of Zoology \& Entomology, University of the Free State, Bloemfontein 9300, South Africa
} 
K.B. Kunt, R.S. ÖZkÜtüK, M. Elverici, Y.M. Marusik, and G. Karakaş

Table 1. Leg measurements of Harpactea karaschkhan sp. n. (Holotype $\odot$ / Paratype $\odot)$.

\begin{tabular}{lcccccc}
\hline Leg & $\mathrm{Fe}$ & $\mathrm{Pa}$ & $\mathrm{Ti}$ & $\mathrm{Me}$ & $\mathrm{Ta}$ & Total \\
\hline I & $1.60 / 1.64$ & $1.00 / 1.08$ & $1.20 / 1.48$ & $1.12 / 1.36$ & $0.40 / 0.50$ & $5.32 / 6.06$ \\
II & $1.50 / 1.60$ & $0.83 / 1.04$ & $1.25 / 1.32$ & $1.00 / 1.16$ & $0.38 / 0.38$ & $4.96 / 5.50$ \\
III & $1.20 / 1.40$ & $0.63 / 0.72$ & $0.95 / 1.20$ & $1.15 / 1.28$ & $0.42 / 0.44$ & $4.35 / 5.04$ \\
IV & $1.60 / 1.80$ & $0.80 / 0.92$ & $1.36 / 1.60$ & $1.78 / 1.96$ & $0.43 / 0.55$ & $5.97 / 6.83$ \\
\hline
\end{tabular}

$\mathrm{Fe}=$ femur, $\mathrm{Pa}=$ patella, $\mathrm{Ti}=$ tibia, $\mathrm{Me}=$ metatarsus, and $\mathrm{Ta}=$ tarsus.

mentioned diagnostic characters, the vulva of $H$. karaschkhan sp. n. is unique.

Derivatio nominis: Karaş Han is God of Darkness in Turkish and Altaic mythology.

Measurements [Holotype $\&$ / Paratype ?]: AL 2.00 / 2.40; CL 1.83 / 2.04; CWmax 1.30 / 1.40; CWmin 0.80 / 0.88; ChF 0.44 / 0.51; ChG 0.33 / 0.35; ChL 0.81 / 0.90. Leg measurements are given in Table 1.

Description of holotype female: Small-sized spider. Carapace yellow-light brown, darker in the cephalic region, smooth, covered with sparsely distributed brownish hairs, longer and directed forward in the cephalic region. Fovea indistinct. Eyes absent (Figs. 1a,b). Labium, gnathocoxae, and chelicerae reddish-brown. Sternum dirty yellow, brownish at edges. Sternum, labium, gnathocoxae, and chelicerae covered with brownish hairs of similar type and density (Fig. 1c). Cheliceral groove with four teeth, retromarginal teeth smaller than promarginal teeth. Among retromarginal teeth, the proximal tooth is conical and located a bit distally compared to the interspace between the promarginal teeth; the distal tooth is triangular, larger than the other and located at the middle of the cheliceral groove (Fig. 1d). Abdomen yellowish, cylindrical, covered with fine brown hairs.

Legs same color as abdomen. All legs with brownish discoloration at articular points of trochanter with coxa and femur. Tarsus with three tarsal claws. Numbers of denticles on tarsal claws: over 10 on legs I and II; 2 on leg III; absent on leg IV. Scopulae weakly developed, almost absent on tarsus and metatarsus of legs III and IV. Anterior femora with numerous prolateral and dorsal spines (Figs. 1e,f) and one to three prominent retrolateral spines; posterior femora with many spines; one prolateral spine on patella II; four spines on the dorsal side of patellae III and IV; three or four ventral and prolateral spines on tibia II; posterior tibiae and metetarsi with many spines; one dorsal spine on coxa III. Leg formula 4123. Details of leg spination are given in Table 2.

Vulva: Vulva almost equally sclerotized on the entire surface. Distal crest slightly longer than a rod-shaped part of spermatheca, expanding towards apical with comparatively less sclerotized apex (Figs 2a,b). Rod-shaped part of spermatheca short and thick. Distal expansion of the spermateca circular. Basal transverse part of the anterior spermatheca narrow and V-shaped. "Anterior basal arc" wing-shaped. Anterior sides more strongly sclerotized than other parts. Transverse bar relatively straight, thin. Membranous sac extremely wide; about three times longer than anterior spermatheca (Figs. 2c,d).

Distribution: Harpactea karaschkhan sp. n., is only known from its type locality.

Comments: New species belongs to the genus Harpactea based on the position of cheliceral teeth and structure of the vulva. According to the classification of DeelemanReinhold (1993), the new species belongs to the rubicunda (D) group by having a wide membranous sac on the vulva and spines on coxa III and patella III. Presence of spines on the patellae and the tibiae of the second pair of legs and presence of retrolateral spines on the anterior femora are very unusual characters for the genus Harpactea.

Biospeleological notes: Yalandünya cave is located at the foothills of the Taurus Mountains. The cave is formed in bluish-gray Paleozoic (Permian) limestone. It is a $270 \mathrm{~m}$ long cave, open for tourists, which starts with a $50 \mathrm{~m}$ long corridor sloping from south to north. Following the entrance of the cave at the start of the corridor, the following spiders were observed: numerous Loxosceles rufescens (Dufour, 1820) (Sicariidae), several Heteropoda variegata (Simon, 1874) (Sparassidae), and some exuviae of Chaetopelma sp. (Theraphosidae). Also, funnel webs of Tegenaria sp. (Agelenidae) were seen along the corridor between or beneath large rocks. At the end of the corridor, a wide chamber continues eastward. Bat colonies were observed in this chamber [three species, according to Benda and Horáček (1998): Eptesicus bottae Peters, 1869; Pipistrellus savii (Bonaparte, 1837), and Plecotus austriacus (Fischer, 1829)], together with a dense population of a cricket Ovaliptila beroni (Popov, 1975) (Orthoptera: Gryllidae) on the cave floor. Terrestrial isopods were observed on the extensively damp walls of the chamber and also under rocks on the ground, together with troglomorphic silverfish Coletinia sp. (Zygentoma: Nicoletiidae). The cave continues northward with an initially narrow corridor. At the entrance of this corridor, webs of Cataleptoneta sp. (Araneae: Leptonetidae) were present on stone walls. One adult male of Charinus ioanniticus (Kritscher, 1959) (Amblypygi: Charinidae) was also collected in this corridor between large rocks on the ground on January 5, 2013. This corridor is followed by a second, terminal chamber, not as wide as the previous one. 


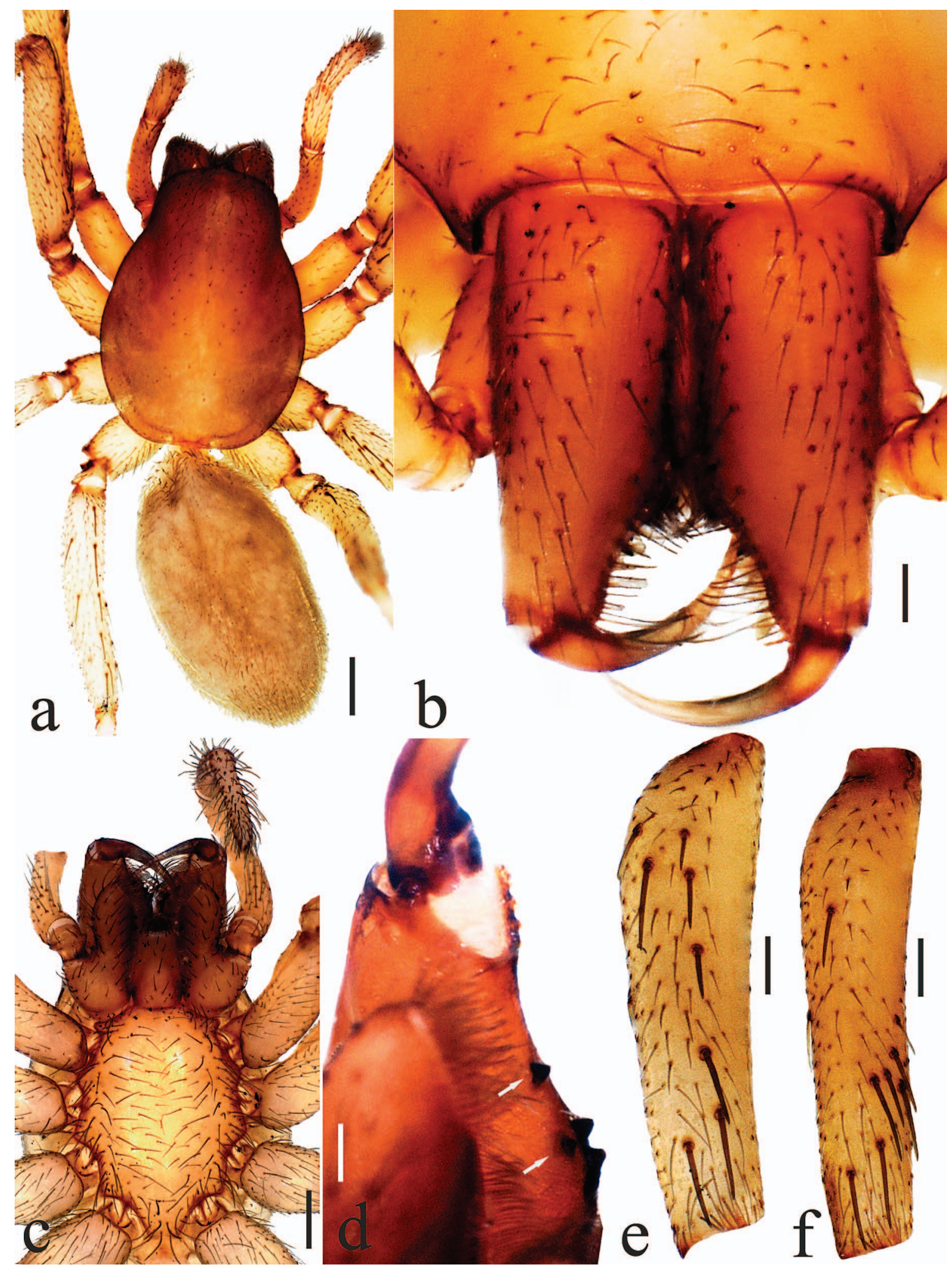

Figure 1. Harpactea karaschkhan sp. n. a. General habitus, dorsal view; b. Cephalic region of carapace and chelicera, anterior view; c. Sternum and mouthparts, ventral view; d. Cheliceral teeth, posterior-ventral view (arrows indicate the retromarginal teeth); e. Femur I, prolateral view; f. Femur II, prolateral view. Scale lines: a. $0.5 \mathrm{~mm}$; b. and c. $0.4 \mathrm{~mm}$; d. $0.1 \mathrm{~mm}$; and e. and f. $0.25 \mathrm{~mm}$. 
Table 2. Leg spination of Harpactea karaschkhan sp. n.

\begin{tabular}{|c|c|c|c|c|}
\hline o & Leg I & Leg II & Leg III & Leg IV \\
\hline $\mathrm{Cx}$ & 0 & 0 & $0-1 \mathrm{~d}$ & 0 \\
\hline $\mathrm{Fe}$ & $6-9 \mathrm{pl} 2 \mathrm{~d} 1-2 \mathrm{rl}$ & $5-6 \mathrm{pl} \mathrm{3-4} \mathrm{d} 2-3 \mathrm{rl}$ & $2-4 \mathrm{pl} 7-8$ d $3 \mathrm{rl}$ & $3 \mathrm{pl} 6 \mathrm{~d} 3 \mathrm{rl}$ \\
\hline $\mathrm{Pa}$ & 0 & $0-1 \mathrm{pl}$ & $1 \mathrm{pl} 2 \mathrm{~d} 1 \mathrm{rl}$ & $1 \mathrm{pl} 2 \mathrm{~d} 1 \mathrm{rl}$ \\
\hline $\mathrm{Ti}$ & 0 & $1-2 \mathrm{pl} 2 \mathrm{v}$ & $2-3 \mathrm{pl} 1 \mathrm{~d} 2-3 \mathrm{rl} 4 \mathrm{v}$ & $3 \mathrm{pl} 1 \mathrm{~d} 2 \mathrm{rl} 5 \mathrm{v}$ \\
\hline $\mathrm{Me}$ & 0 & 0 & $2 \mathrm{pl} 3 \mathrm{rl} 6 \mathrm{v}$ & $3 \mathrm{pl} 3 \mathrm{rl} 5 \mathrm{v}$ \\
\hline
\end{tabular}

$\mathrm{Cx}=$ coxa, $\mathrm{Fe}=$ femur, $\mathrm{Pa}=$ patella, $\mathrm{Ti}=$ tibia, and $\mathrm{Me}=$ metatarsus

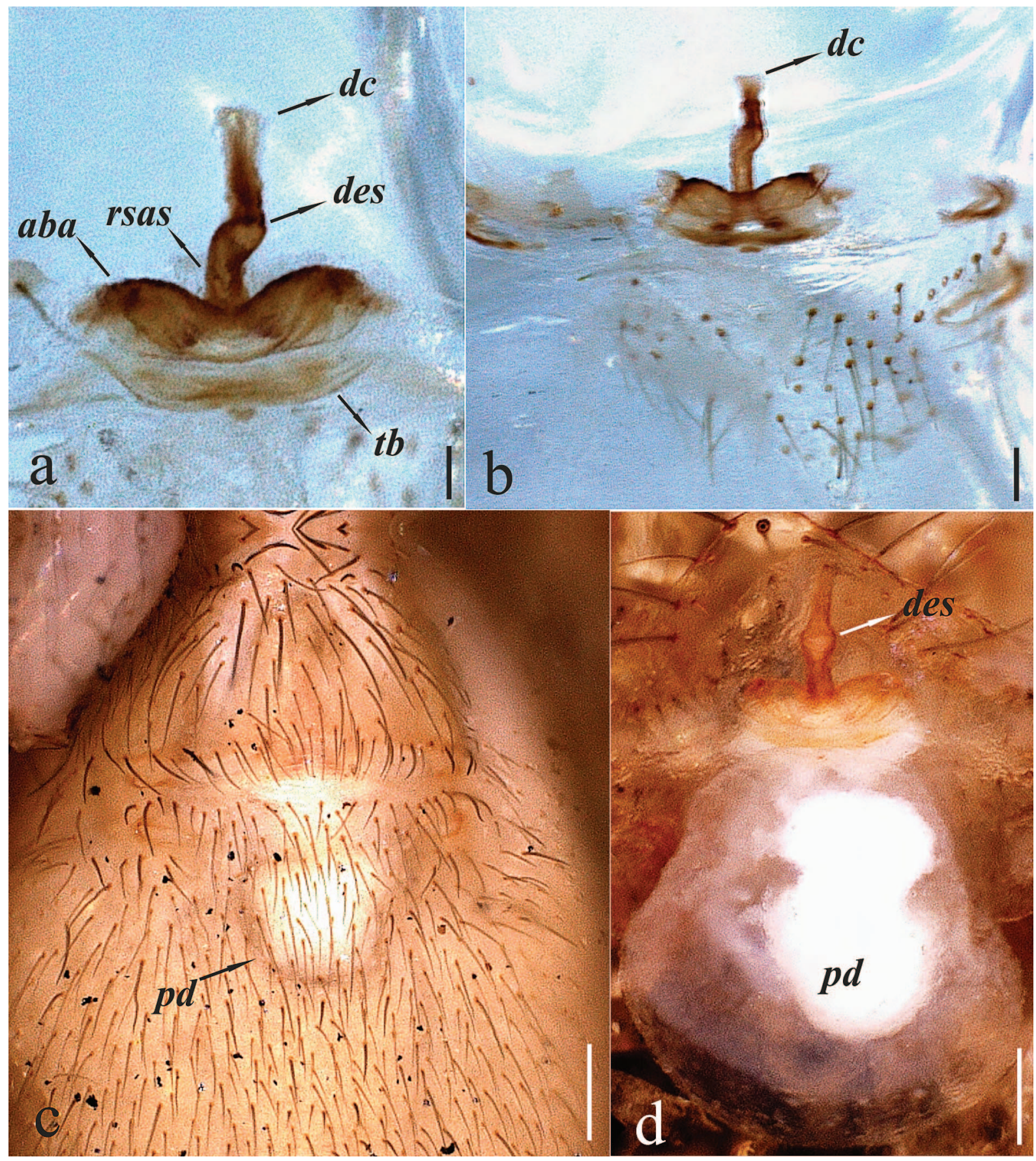

Figure 2. Harpactea karaschkhan sp. n. a,b. Vulva, dorsal view c,d. Vulva, ventral view aba, anterior basal arc; dc, distal crest; des, distal expansion of the spermatheca; $p d$, posterior diverticulum; rsas, rod-shaped part of the anterior spermatheca; tb, transverse bar. Scale lines: a. $0.05 \mathrm{~mm}$; b. $0.1 \mathrm{~mm}$; c. $0.2 \mathrm{~mm}$; and d. $0.25 \mathrm{~mm}$. 
This terminal chamber is completely dark, while the rest of the cave is illuminated for tourists, and apparently more humid, with cave mud on the floor and several large columns inside. The specimens of karaschkhan sp. n. were collected as they were actively wandering on these columns.

\section{ACKNOWLEDGEMENTS}

This work was supported by the Research Foundation of Anadolu University (Project Number: 1503F093). The English of the final draft was kindly checked by Dr. Victor Fet (West Virginia, USA).

\section{REFERENCES}

Benda, P., and Horáček, I., 1998, Bats (Mammalia: Chiroptera) of the eastern Mediterranean. Part 1. Review of distribution and taxonomy of bats in Turkey: Acta Societatis Zoologicae Bohemicae, v. 62, p. $255-313$.

Chatzaki, M., and Arnedo, M.A., 2006, Taxonomic revision of the epigean representatives of the spider subfamily Harpacteinae (Araneae: Dysderidae) on the island of Crete: Zootaxa, v. 1169, p. 1-32.

Deeleman-Reinhold, C.L., 1993, The genus Rhode and the harpacteine genera Stalagtia, Folkia, Minotauria, and Kaemis (Araneae, Dysderidae) of Yugoslavia and Crete, with remarks on the genus Harpactea: Revue Arachnologique, v. 10, p. 105-135.

Porter, M.L., 2007, Subterranean biogeography: What have we learned from molecular techniques?: Journal of Cave and Karst Studies, v. 69, no. 1 , p. 179-186. 